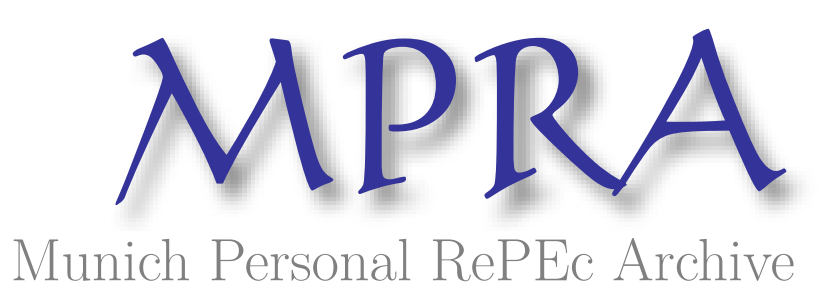

\title{
Exposure at Default Model for Contingent Credit Line
}

Bag, Pinaki

1 April 2010

Online at https://mpra.ub.uni-muenchen.de/20387/

MPRA Paper No. 20387, posted 07 Apr 2010 01:31 UTC 


\title{
Exposure at Default Model for Contingent Credit Line
}

By

\author{
Pinaki Bag *a
}

* Disclaimer:The author is working with Union National Bank (Bank), Abu Dhabi, UAE. The views expressed in the article are personal and do not represent the views of the Bank and the Bank is not responsible towards any party for these views.

a Author E-Mail:pinakibag@gmail.com, Author Telephone:+971-509343837 


\begin{abstract}
In-spite of large volume of Contingent Credit Lines (CCL) in all commercial banks paucity of Exposure at Default (EAD) models, unsuitability of external data and inconsistent internal data with partial draw-down, has been a major challenge for risk managers as well as regulators for managing CCL portfolios. Current paper is an attempt to build an easy to implement, pragmatic and parsimonious yet accurate model to determine exposure distribution of a CCL portfolio. Each of the credit line in a portfolio is modeled as a portfolio of large number of option instrument which can be exercised by the borrower determining the level of usage. Using an algorithm similar to basic CreditRisk+ and Fourier Transforms we arrive at a portfolio level probability distribution of usage.
\end{abstract}

JEL Classification: G20, G21, C13

Keywords: EAD, Basel II, Credit Risk, Contingent credit line (CCL) 


\section{Introduction}

Bank for International Settlement (BIS) in its Basel II guidelines ${ }^{1}$ describes capital as a function of Probability of Default (PD), Loss Given Default (LGD) and Exposure at Default (EAD) with all playing an equally vital role, but a simple Google search on each term returns 5.7 Million, 65 Thousand and 29 Thousand $^{2}$ hits respectively. Google search may not be concrete enough to conclude but it does indicate the trends in terms of importance given to each component by academicians and practitioners. Similar assertions are made by Financial Services Authority $(\mathrm{FSA})^{3}$, UK regarding EAD models as well.

Contingent Credit Lines (CCL) or Loan Commitments ${ }^{4}$ are contractual promises by the bank to specific obligors to lend up to specified limits on pre-determined rates and terms. They are generally accompanied with different fees which must be paid over the life of the commitment, and the material adverse change (MAC) clause which states that bank may cancel the line if the credit quality deteriorates of the specific obligor.

According to Federal Deposit Insurance Corporation survey ${ }^{5}$ close to $80 \%$ of all commercial and industrial loans are done using commitment contracts and as of

1 Refer BCBS (2006) revised document on Basel II guideline

2 Searched on 24 Feb 2010 from www.google.com

3 Please refer EAD Expectation Note (2007)

4 Contingent Credit Line, Loan/Credit Commitment, Line of Credit has been used interchangeably in the paper

5 For details see Federal Deposit Insurance Corporation, Statistics on Banking, table RC-6 (November 2009) 
September 2009, the outstanding (unused) CCLs of U.S. firms were close to $\$ 1.9$ trillion. Avery and Berger (1991) states that main reason for using credit commitment is to provide flexibility during slowdown and as noted by Kanatas (1987) these can be seen as hedging instruments. Hawkins (1982) comments that credit lines help borrowers manage fluctuations in working capital but Sufi (2008) reports that firm with low cash flow or high cash flow volatility rely more heavily on cash rather than credit line.

Basel II guidelines calculate regulatory capital charge of contingent credit commitments based on credit conversion factor $(0 \%$ to $50 \%)$ and the Risk Weight $(0 \%$ to $100 \%)$. As noted by Hull (1989), credit conversion factor (CCF) for a small bank underestimates the capital requirement as "fat tails" effect increases the capital requirement proportionately more for off-balance sheet items. In its Advanced Internal Rating Based (AIRB) methodology Basel II does allow banks to compute its own estimates of CCF and henceforth its own estimate of Exposure at Default (EAD) for CCL.

Apart from negligence of EAD models by consultants and academics leading to a paucity of external data and models, other issues identified by FSA, has been scarcity of usable data regarding draw-downs in each bank and unsuitability of external data. When external data is available the suitability is always questioned as the estimates will be strongly influenced by lender's behavior.

The current paper is an attempt to build an easy to implement, parsimonious yet 
accurate model for estimation of exposure for CCL portfolio. Each $C C L$ is modeled as portfolio of options with the obligors which they can exercise with the bank at prespecified terms \& conditions. Modeling the exercise of options as a Poisson process, a stochastic distribution of exposure at different segment of portfolio level has been constructed. A standard Fast Fourier Transform algorithm is used to convolute these portfolio segments and generate the exposure probability distribution of the complete portfolio.

This model with help from internal research of the bank can be used for the estimation of EAD for banks as mandated by Basel II for CCL portfolios. Apart from regulatory requirement, stochastic exposure distribution generated can form as an input for different economic capital model and stress testing procedures to capture accurate risk profile of the portfolio. This will also contribute in providing better insights in the problem of managing liquidity risk for portfolio of CCL e.g. credit card portfolio or Home Equity Line of Credit (HELC) portfolio.

In the following pages we will see in section II about past studies related to CCL, section III will detail on how we can use options executions to link the draw-downs in a portfolio, section IV provides an implementation with hypothetical portfolios and finally section $\vee$ concludes with potential future research areas and implications.

\section{CCL, Options \& Partial Draw-down}

To estimate EAD for CCL there are two standard form of equation used. In the 
first form an appropriate conversion factor is multiplied with the total limit (TL) of the facility.

$$
E A D=C F . T L
$$

In the second form an appropriate conversion factor $(\alpha)^{6}$ is multiplied with the unused part of the limit $(L)$ of the facility.

$$
E A D=\text { CurrentExposure }+\alpha \quad \cdot L
$$

As shown by Moral (2006) both will yield same results for EAD except when full utilization is in place. As discussed by Miu and Ozdemir (2008) Basel CCF is equivalent to $\alpha$ in equation (2). We will use equation (2) for all our subsequent analysis. As current exposure and $L$ are known modeling $\alpha$ i.e. partial draw-down of the unused limit will give us clear insight into the problem of EAD estimation of CCL.

Studies related to $\mathrm{CCL}$ are concentrated around pricing of $\mathrm{CCL}^{7}$ and level of partial draw-down in each credit line. In the current endeavor we will concentrate on latter.

Thakor et al. (1981) utilize a put option ${ }^{8}$ approach to price the loan commitments and measure the sensitivity of these values to changes in interest rates. Partial drawdown on CCL is explained through, interest elasticity of demand for borrowed funds and

6 This is also referred as Loan Equivalent amount (LEQ) in many literatures.

7 Pricing of CCL option theoretic approach has been used by Loukoianova et al. (2006), Chateau (1990), Chateau and Wu (2003).

8 In this case the Bank is buying the put option from the obligor as the obligor is selling its debt to the bank by availing the credit lines on pre-specified terms and conditions. 
bank customer relationship dynamics. A firm with infinite opportunities for investment and no restriction on capital structure or leverage, the interest elasticity will be perfectly elastic and vice-versa. Alternatively if we look into the bank customer relationship framework, customer will try to minimize the expected cost of renewal of the line in next year and opportunity loss of not utilizing the full facility this year when availing the line.

Kaplan and Zingales (1997) find that the un-drawn portion of credit lines decreases when firms are more liquidity constrained. Gatev and Strahan $(2003)^{9}$ report that partial draw-downs increase when the commercial paper - $\mathrm{T}$ bill rate spread rises. Both of these studies indicate presence of interest incentive framework for partial drawdown which inspired Jones and Wu (2009) for using the same for modeling partial drawdown. They models credit quality as a jump-diffusion process while partial draw-down and pricing of CCL is done as a function of dynamic credit state. The proportion of the credit line drawn is modeled as function of the difference between alternative opportunity rate and the marginal cost of line borrowings. Opportunity rate is defined as the rate of interest charged to the borrower if she borrows outside the purview of the defined credit line. To incorporate linking of loan spread to the credit default swap spread of the borrower, marginal cost of borrowing is defined as function of reference rate, contractual spread over reference rate and proportion of the excess that is added to current period loan. Apart from the interest rate differential, sensitivity of drawdown with interest rate differential is included to model amount of partial draw-down. This

9 They used a sample from the set of all commercial paper backup lines of credit on for large US Corporation in period 1Q $1991-1 \mathrm{Q} 2002$, for a total of 2,695 commitments. 
sensitivity is similar to the interest elasticity proposed by Thakor et al. (1981).

Both of the approach (Thakor et al. (1981) and Jones et al. (2009)) looks intuitive and convincing but implementing the same in banks where most of the CCL are extended to unrated obligors whose market spread may not be easily available, might pose problems of parameterization. Some parameter like interest elasticity may be affected by firm specific behavior as well as present macro economic variables. Another approach of estimating usage of limits under continuous-time model where the credit provider and the credit taker interact within a game-theoretic framework has been attempted by Leippold et al (2003).

Attempts to directly estimate partial draw-down has also been undertaken in past. Asarnow and James (1995) present partial draw-down estimates based on credit lines issued by Citibank to publicly-rated North American firms over the five-year period from 1987 to 1992 . They found a downward sloping of usage level from high rated obligors to low rated obligors i.e. lower rated firms would have already consumed their credit lines earlier than when it approaches default. Similar trend is also noted by Araten and Jacobs (2001) where partial draw-down decreases as the firm approaches default. Their estimates of partial draw-down is based on 1,021 observations (408 facilities of 399 borrowers) at a quarterly frequency in the period 1Q 1995 - 4Q 2000 for Chase borrowers. They also report that level of usage has been affected by risk rating but not by commitment size and borrower industry. Jacobs (2008) empirical study is based on dataset encompassing 281 defaulted instruments from 720 U.S. borrowers with public 
credit ratings over the period from 1985 to 2006 . He finds that similar trends in terms of usage and points out statistically significant affect of obligor profits in the level of usage.

Agarwal et. al. (2005) examined utilization of HELC in US market and confirms that borrowers with deteriorating credit quality increase their utilization. Jiménez et al. (2009) reports a credit line usage of different firms granted by banks in Spain between 1984 and 2005. The final dataset used consisted of 696,445 credit lines granted to 334,442 firms by 404 banks. They reported variety of factors such as commitment size; collateralization and maturity of the CCLs affect the usage level. They also report a statistically significant higher usage rate for firms that are defaulting at least 3 years prior to default and the usage monotonically increases as the default approaches for these firms.

Level of usage is mainly affected by two distinct forces, the lender might realize the deteriorating credit quality of the borrower and cut back the limits thereby increasing the utilization ratio or the borrower may actually use up the line before the lender realizes deteriorating credit quality. As indicated by Qi (2009) with credit card usage in US, borrowers are more active than lenders in this game of "race to default." Martin and Santomero (1997) analyzes the pricing of CCL from demand side of firms and show that credit line usage depends on business growth potential of the firm as well as the uncertainty involved in those investment opportunities. External macro economic variables, size of credit line, collateralization etc. may also determine level of partial draw-down of obligors. 


\section{Partial Draw-down at Portfolio Level}

To put ourselves on firmer basis lets define a bank B with a CCL portfolio of $\mathrm{N}$ obligors each having one facility of CCL each. Each of these credit lines with the bank can be used before the expiry of the contract. For obligor $A$ with CCL size of $L_{A}$ we can safely assume that $A$ has infinite number of put options which she can choose to exercise and the number of instrument she will exercise will decide the level of partial draw-down. If she exercises all the puts, than she will have consumed her whole limit. We assume she has $n$ number of puts at her disposal, where $n$ is sufficiently large. Also size of each put can be given as

$$
Q_{A}=\frac{L_{A}}{n}
$$

So the amount of partial draw-down can be given as $r X Q_{A}$ where $r$ is the number of puts exercised by $\mathrm{A}$ in the time frame of consideration. So the probability generating function (PGF) of the option exercise can be defined as follows:

$$
F_{A}(z)=P(r=0) Z^{0}+P(r=1) Z^{1}+P(r=2) Z^{2}+P(r=3) Z^{3}+P(r=4) Z^{4} \ldots \ldots
$$

Let's assume expected usage of the CCL is $\alpha_{A}$ so average number of puts used

by $A$ is

$$
\lambda_{A}=\frac{\alpha_{A} L_{A}}{Q_{A}}
$$

Using a Poisson process of exercise of each option we have the PGF given by equation (6) reduces to 
$F_{A}(z)=\frac{e^{-\lambda_{A}} \lambda^{0}}{0 !} Z^{0}+\frac{e^{-\lambda_{A}} \lambda^{1}}{1 !} Z^{1}+\frac{e^{-\lambda_{A}} \lambda^{2}}{2 !} Z^{2}+\ldots \quad=F_{A}(z)=e^{-\lambda_{A}} e^{\lambda_{A} Z}$

For all obligors, $m(m<N)$ in the portfolio having put size equal to $Q$ we have the PGF for $r$ number of puts being used and assuming independence of obligors in exercising of each option

$$
\prod F_{A}(z)=\prod e^{-\lambda_{A}} e^{\lambda_{A} Z}=e^{\sum_{i=1}^{i=m}-\lambda_{i}+\sum_{i=1}^{i=m} \lambda_{i} Z}
$$

Now lets assume the overall average usage in the portfolio is $\alpha$ and unused limits in this portfolio of $m$ obligor be $L_{i}$ hence we have

$$
\alpha=\frac{\sum_{i=1}^{i=m} \alpha_{i} L_{i}}{\sum_{i=1}^{i=m} L_{i}}
$$

Let $S_{i}=\sum_{i=1}^{i=m} \lambda_{i}$ and as we have assumed all the size of put is $Q_{i}$ henceforth and let

$$
\beta_{i}=\sum_{i=1}^{i=m} S_{i} \cdot Q_{i} \quad \text { so } \quad S_{i}=\sum_{i=1}^{i=m} \lambda_{i}=\frac{\sum_{i=1}^{i=m} \alpha_{i} L_{i}}{Q_{i}}=\frac{\alpha}{Q_{i}} \cdot \sum_{i=1}^{i=m} L_{i} \text { hence } \beta_{i}=\alpha \cdot \sum_{i=1}^{i=m} L_{i}
$$

So the PGF of usage being equal to $\mathrm{X} Q$ will be given by

$$
F_{Q I}(z)=e^{(Z-1) S_{I}}=e^{-S_{l}}\left[\frac{\left(S_{1} z\right)^{0}}{0 !}+\frac{\left(S_{1} z\right)^{1}}{1 !}+\frac{\left(S_{1} z\right)^{2}}{2 !}+\ldots\right]
$$

Now for any real portfolio, $Q$ will not be equal for all obligors. To simplify our calculation we will segregate the whole portfolio in different sub-portfolios, such that 
obligors in each sub-portfolio will have same size of put as $Q_{i}$. Since in each subportfolio $Q_{i}$ is same whenever there is exercise of 1 put there is usage of $1 X Q_{i}$ and if there is exercise of 2 puts there is usage of $2 X Q_{i}$ so we can write:

$$
P\left(\text { usage }=r \cdot Q_{i}\right)=P(r \text { puts being used })
$$

So the PGF of the sub-portfolio usage can be written as:

$$
\begin{gathered}
F_{Q i}(Z)=\sum_{r=0}^{\infty} P\left(\text { Usage }=r \cdot Q_{i}\right) Z^{r \cdot Q_{i}}=\sum_{r=0}^{\infty} P(\text { Usage }=r) Z^{r \cdot Q_{i}} \\
F_{Q_{i}}(z)=\sum_{r=0}^{\infty} e^{-S_{i}} \frac{S_{i}^{r}}{r !} Z^{r \cdot Q_{i}}=e^{-S_{i}} e^{S_{i} Z^{Q_{i}}}
\end{gathered}
$$

Hence to find the usage distribution of the whole portfolio we must convolute each of these sub-portfolios. Hence form equation (11) for the whole portfolio with t subportfolios PGF can be written as (assuming independence of each sub-portfolio):

$$
F_{Q}(z)=\prod_{i=1}^{t} F_{Q_{i}}(z)=\prod_{i=1}^{t} e^{-S_{i}} e^{S_{i} Z^{Q_{i}}}=e^{-\sum_{i=1}^{t} S_{i}+\sum_{i=1}^{t} S_{i} z^{Q_{i}}}
$$

Now to determine the exposure distribution of the portfolio we can have from Taylor's theorem

$$
\begin{gathered}
P\left(\text { Usage }=r \cdot Q_{i}\right)=\left.\frac{1}{r !} \frac{d^{r}\left(F_{Q}(z)\right)}{d z^{r}}\right|_{Z=0} \text { for } r=0,1,2, \ldots \\
\text { Let } W_{r}=\left.\frac{1}{r !} \frac{d^{r} F_{Q}(Z)}{d z^{r}}\right|_{Z=0}=\left.\frac{1}{r !} \frac{d^{r-1}}{d z^{r-1}} \frac{d\left(F_{Q}(Z)\right)}{d z}\right|_{Z=0}
\end{gathered}
$$

As $\sum_{i=1}^{t} S_{i}$ is constant hence: 


$$
W_{r}=\left.\frac{1}{r !} \frac{d^{r-1}}{d z^{r-1}}\left(F_{Q}(Z) \cdot \frac{d\left(\sum_{i=1}^{t} S_{i} Z^{Q_{i}}\right)}{d z}\right)\right|_{z=0}
$$

By Lebinitz's formula for $\mathrm{n}^{\text {th }}$ order differentiation we can have:

$$
W_{r}=\left.\frac{1}{r !} \sum_{k=0}^{r-1}{ }^{r-1} C_{k} \cdot \frac{d^{r-1-k} F_{Q}(Z)}{d z^{r-1-k}} \cdot \frac{d^{k+1}\left(\sum_{i=1}^{t} S_{i} Z^{Q_{i}}\right)}{d z^{k+1}}\right|_{Z=0}
$$

If $Q_{i}=K+1 \& Z=0$ then

$$
\frac{d^{k+1}\left(\sum_{i=1}^{t} S_{i} Z^{Q_{i}}\right)}{d z^{k+1}}=(k+1) ! S_{i}
$$

else if $Q_{i} \neq K+1$

$$
\frac{d^{k+1}\left(\sum_{i=1}^{t} S_{i} Z^{Q_{i}}\right)}{d z^{k+1}}=0
$$

And we have from equation (18)

$$
W_{r-1-k}=\left.\frac{1}{(r-1-k) !} \frac{d^{r-1-k} F_{Q}(Z)}{d Z^{r-1-k}}\right|_{Z=0}
$$

Hence combining equation (20), (21), (22) and (23) at $Z=0$ we have

$$
W_{r}=\left.\frac{1}{r !} \sum_{k=Q_{i}-1}^{r-1}{ }^{r-1} C_{k} \cdot(k+1) ! S_{i} \cdot(r-1-k) ! W_{r-1-k}\right|_{Z=0} \quad=\frac{1}{r} \sum_{i ; Q_{i} \leq r} Q_{i} \cdot S_{i} \cdot W_{r-Q_{i}}
$$

Hence from (24) and (10)

$$
W_{r}=\frac{1}{r} \sum_{i ; Q_{i} \leq r} \beta_{i} \cdot W_{r-Q_{i}}
$$

Now if we have $Q_{i}$ with integers starting from 1 to a large enough integer we can 
get the complete probability distribution of portfolio usage, starting from $W_{0}=\sum_{i=1}^{t} S_{i}$.

If we let $Q_{i}$ vary from 1 we will have exposure distribution from $1 \$$ as seen from equation (3) $Q_{i}$ represents the size of each put.

Till now we have used a constant $\alpha$ for the whole portfolio, in reality we will have a portfolio where $\alpha$ will be different for each segment of the portfolio depending upon product type, and other factors etc. As noted in a survey ${ }^{10}$ banks generally prefer to use segment wise $\alpha$ for its EAD estimation. Hence after performing the computation till equation 25 we will be left with probability distribution of usage for different segments of the portfolio. To finally arrive at a portfolio level exposure distribution we will follow a standard convolution procedure using Fourier Transforms.

For simplicity lets assume we have only two distinct segment of the CCL portfolio and from (25) we can have two distinct vectors $\left(F=f_{0}, f_{1}, \ldots . f_{-1} \& \quad G=g_{0}, g_{1}, \ldots . g_{m-1}\right)$ representing the probabilities of usage for each segment. Let $\mathrm{R}$ represent the vector formed by convolution of $F$ and $G$. To perform Fast Fourier Transform (FFT) ${ }^{11}$ we will pad each of the vector such that length of each vector is $s$, where $s=>1+m$ and $s$ is of the form $2^{\mathrm{x}}$ where $\mathrm{x}$ is an integer. We know from convolution theorem that

$$
R=F \otimes=\text { Inverse FFT } \quad(F F T(F) . F F T(G))
$$

Hence $\mathrm{R}$ will give us the overall portfolio usage probability distribution. The procedure can easily be replicated if we have more than two segments in our portfolio.

10 See RMA Survey (2004) on estimation of EAD \& LGD

11 For details on Convolution using FFT please refer Mario (2004) and Robertson (1992) 


\section{Numerical Experiment}

For a typical CCL portfolio, $\Sigma S_{i}$ for the whole portfolio may be quite large and we are trying to assign probability to each dollar of usage in the algorithm so it may finally turn out to be daunting task to achieve the full distribution. For the calculation of negative exponential of a very large number $\left(\Sigma S_{i}\right)$ for initiation of the calculation (as $W_{0}$ ) we will soon be confronted with precision issues under double-precision ${ }^{12}$ regime of most common software applications. Most applications including Matlab, Octave or Microsoft Excel under default settings will approximate $W_{0}$ as zero and as the distribution depends on $\mathrm{W}_{0}$ for derivation of full distribution, the full distribution would be evaluated incorrectly.

There may be many alternative to circumvent the problem in standard applications. One solution to this problem may be use of libraries which can handle very high precision calculation ${ }^{13}$. This may also require higher computational power in terms of hardware as well, the specification of which is beyond the scope of the current paper.

For illustration ${ }^{14}$ we have chosen two sample segments ${ }^{15}$ of 20 obligors each with of $\alpha=10 \%$ and $\alpha=40 \%$ respectively with limits ${ }^{16}$ of each obligor varying from $\$ 2,266$ to $\$ 96,330$. Each of the obligor limit is divided into 1,000 puts. The figure in appendix B illustrates that the usage distribution of each segment and final convoluted portfolio; the

12 For details see Monniaux (2008)

13 See http://gmplib.org/ for details

14 The calculations are done using Linux based Genius 1.0.7 as arbitrary precision calculator and Linux based Octave for FFT and final distribution evaluation.

15 Details of the portfolio presented in appendix A

16 The limits are chosen by using Microsoft Excel's random number generation function between $\$ 500$ and $\$ 100,000$ 
descriptive statistics of each of the distributions are presented in table 3 of appendix B for reference.

To explore the affect of choice of $n$ in the exposure distribution we use first five obligors of portfolio A. The results of the experiment are summarized in Table 3 in appendix C. As noted the standard deviation of the usage distribution decreases as we increase the number of puts used. This may be explained by the fact that we are implicitly assuming a known value of $\alpha$ in our modeling i.e. a zero volatility of $\alpha$ and this fact is becoming more prominent once we start increasing the number of puts (n) i.e. more like real life scenario. The mean value remain relatively stable but the extreme points converge towards the mean to produce a shrinkage in the distribution shape.

Another prime variable in the algorithm is the value set for $\alpha$, we vary the value of $\alpha$ to find its affect on the final distribution. The results of the same are summarized in Table 4 in appendix C. For our 5 obligor portfolio we see increase in the usage level also increase the volatility associated.

To incorporate volatility of $\alpha$ explicitly in the model we can also use a mixed Poisson process where we chose different values of $\lambda$ from an assumed distribution. More commonly used mixture distribution has distribution of $\lambda$ as Gamma distribution, resulting in negative binomial; this has the advantage of analytically tractable two parameter distribution. Similar combination ${ }^{17}$ can be used to incorporate volatility of $\alpha$ explicitly in each segment of the portfolio.

17 See Karlis and Xekalaki (2005) for various mixed Poisson distributions 
An argument against using any mixed distribution may be that this will induces a second set of assumptions in our model and will require the banks to calculate usage volatility of each segment. In the current model the volatility of the final distribution will depend how spread out the expected usage is between each the segment. This may be more pragmatic approach considering that it will have minimum data requirement at portfolio-segment level and segmentation of the portfolio can be decided with internal research and expert judgment on usage.

One of the segmentation possibilities of the portfolio may be based on commitment fee ${ }^{18}$ and service fee ${ }^{19}$. As shown by Thakor and Udell (1987) when the bank is uncertain about the level of partial draw-down, it may segregate borrowers by keeping high commitment fees and low service fees in one contract and low commitment fees and high service fees in other contract. Former would be attractive to borrowers with higher probability of draw-down as they are more probable to pay a service fee and more interested in having an active credit line, this will not be true for borrowers who are less confident about draw-downs. Contract choice may not be always that simple as discussed by Maksimovic (1990) it may also depend on structure of the borrower's industry, as in imperfect competition presence of predetermined rates of financing in borrowers armory provides enhanced strategic position.

\section{Conclusion}

This paper formulated a parsimonious model for estimation of exposure at

18 commitment fee is an up-front fee paid when the commitment is made

19 an service or annual fee is paid on the borrowed amount 
portfolio level for a typical CCL portfolio by modeling each CCL with a borrower as a portfolio of option instruments. The exercise of each put has been modeled as standard Poisson process where average usage $(\alpha)$ of $C C L$ at the portfolio level is assumed to be known. This value as indicated by Agarwal et. al. (2005), Qi (2009), Jiménez et al. (2009) Gatev et al. (2006) etc. depends on change in credit quality, difference between contractual rate and actual market rate and other factors. Both empirical research and theory suggest a correlation between credit quality and usage of credit line. The algorithm presented here can accommodate different values of $\alpha$, to handle mentioned correlation the portfolio may be segmented in terms of credit quality along with any other criterion decided by the bank. Some of the methods of estimating $\alpha$ has been outlined by Moral (2006) and similar research needs to done on the area of finding expected usage at a given type of portfolio and as indicated earlier, they can work best if the bank themselves does the research on internal data, as this will be highly influenced by Bank's behavior in catching early signs of deterioration in credit quality. Further work may also be needed so that stable distribution parameters can be determined which will not be affected by choice of number of puts used.

Most of the current credit risk model viz. JP Morgan's CreditMetrics, KMV Portfolio Manager, CSFB CreditRisk $+^{20}$ has constant exposure as an input to calculate credit Value-at-Risk. Rosen and Marina (2002) describes that stochastic exposures make a notable difference in credit economic capital calculation. Akkaya and Wagner

20 For details see Gordy (2000) or Crouhy, Galai and Mark (2000) for a comparison of some credit risk models. 
(2003) describe stochastic exposure in CreditRisk+ modeling framework. Stochastic Exposure generated from the discussed model can be useful in improvement of credit economic capital modeling for CCL portfolio.

Accurate exposure calculation is fundamental for liquidity risk management as well, e.g. credit card portfolio or HELC where all the accounts has a un-drawn but committed line pose a challenge to risk managers in terms of expected usage and henceforth liquidity positions; the algorithm presented here may prove helpful in providing meaningful insight into the problem.

The other implication of the algorithm is in the area of EAD estimation for Basel II. As pointed out earlier compared to PD estimation, limited research has gone in estimating EAD. This can provide a good starting point for the banks under AIRB approach of Basel II. Finally this may also be used in terms of stress testing tool to determine worst case liquidity scenarios for the portfolio. As we have the complete distribution of the usage value we can get a good estimate of our worst case scenarios from $99^{\text {th }}$ or $99.9^{\text {th }}$ percentile depending upon the risk appetite of the bank.

Further work needs to be done to improve the algorithm so as to use it in standard software applications with minimized hardware requirements. This will greatly help in quick and smooth implementation of the otherwise intuitive model. 


\section{Reference}

[1] Agarwal, S., and Ambrose, B. "Credit lines and credit utilization." Journal of Money, Credit and Banking 38(1) (2006): 1-22.

[2] Akkaya, N., Kurth, A. and Wagner, A. "Incorporating default correlations and severity variations" in M. Gundlach and F. Lehrbass [13]

[3] Araten, Michel and Michael Jacobs, Jr. "Loan Equivalents for Revolving Credits and Advised Lines." The RMA Journal, (2001): 34-39.

[4] Asarnow, E. and Marker, E. "Historical Performance of the U.S. Corporate Loan Market: 1988-1993," Commercial Lending Review, 10(2), (1995): 13-32.

[5] Avery, Robert B., and Alan N. Berger. "Loan Commitments and Bank Risk Exposure." Journal of Banking and Finance 15, (1991):173-192

[6] Basel Committee of Banking Supervision, "Basel II: International convergence of capital measurement and capital standards: a revised framework." Available at www.bis.org/publ/bcbs118.htm, 19 Nov. 2009.

[7] Board of Governors of the Federal Reserve System, (2009) "Survey of Terms of Business Lending." Federal Reserve Board Statistical Releases, E.2 Available at http://www.federalreserve.gov/releases/e2/current/default.htm, 21 Nov. 2009

[8] Chateau, John Peter D and Jian Wu (2004) "Basle II Capital Adequacy: Computing the 'Fair' Capital Charge for Loan Commitment 'True' Credit Risk." EFMA 2004 Basel Meetings Paper. Available at SSRN: http://ssrn.com/abstract=497546

[9] Château., John-Peter D. "Valuation of 'capped' variable rate loan commitments" Journal of Banking \& Finance Volume 14, Issue 4, (1990):717-728

[10] Credit Suisse, (1997). CreditRisk+: A Credit Risk Management Framework. Credit Suisse Financial Products. Available at www.csfb.com/creditrisk, 1997.

[11] Crouhy, M., D. Galai, and R. Mark. "A Comparative Analysis of Current Credit Risk Models." Journal of Banking and Finance 24 (2000):59-118.

[12] Ergungor, Ozgur E., 2001, Theories of bank loan commitments: A literature review, Federal Reserve Bank of Cleveland Economic Review 37, 2-19.

[13] Monniaux, David., "The pitfalls of verifying floating-point computations." TOPLAS, (2008) 
[14] M. Gundlach and F. Lehrbass (eds.), CreditRisk+ in the Banking Industry, Springer-Verlag, Berlin, Heidelberg, 2004.

[15] D. Karlis and E. Xekalaki, "Mixed Poisson distributions," International Statistical Review, vol. 73, no. 1, (2005):35-58

[16] Federal Deposit Insurance Corporation, Statistics on Banking, (2009) table RC-6 Available at http://www2.fdic.gov/SDI/main4.asp

[17] Financial Services Authority, UK. Comments on EAD models (2007). EAD Expectation Note. Available at http://www.fsa.gov.uk/pubs/international/ead_models.pdf

[18] Gatev, Evan and Philip Strahan, "Banks Advantage in Hedging Liquidity Risk: Theory and Evidence from the Commercial Paper Market." Journal of Finance 61, (2006):867-892.

[19] Gordy, M. B., "A Comparative Anatomy of Credit Risk Models." Journal of Banking and Finance 24 (2000):119-149.

[20] Hull, J., "Assessing Credit Risk in a Financial Institution's Off-Balance Sheet Commitments." Journal of Financial and Quantitative Analysis, 24(4), (1989): 489-501.

[21] Jacobs, M., Jr., "An Empirical Study of Exposure at Default," Manuscript, Office of the Comptroller of the Currency, U.S. Department of the Treasury. (2008)

[22] Jimenez, Gabriel, Jose A. Lopez, and Jesus Saurina, "Empirical analysis of corporate credit lines", Working Paper, Banco de Espana and Federal Reserve Bank of San Francisco.(2008)

[23] Jones, Robert, Yan Wendy Wu Analyzing credit lines with fluctuating credit quality. Working Paper, The Bank of Canada - Simon Fraser University Conference on Financial Market Stability. (2009)

[24] Kanatas, George., "Commercial Paper, Bank Reserve Requirements, and the Informational Role of Loan Commitments." Journal of Banking and Finance 11, (1987):425-448

[25] Kaplan, Steven and Luigi Zingales "Do Investment-Cash Flow Sensitivities Provide Useful Measures of Financing Constraints?" Quarterly Journal of Economics 112, (1997):169-215.

[26] Loukoianova, Elena., Salih N. Neftci, and Sunil Sharma "Pricing and Hedging of Contingent Credit Lines ,"IMF Working Paper,WP/06/13, (2006) 
[27] M. Leippold, S. Ebnoether, P. Vanini, "Optimal Credit Limit Management," National Centre of Competence in Research Financial Valuation and Risk Management, Working Paper No. 72. (2003)

[28] Maksimovic, V. "Product Market Imperfections and Loan Commitments," Journal of Finance, vol. 45 (1990), pp. 1641-54.

[29] Martin., J. Spencer and Anthony M. Santomero "Investment opportunities and corporate demand for lines of credit, "Journal of Banking \& Finance, Volume 21, Issue 10, (1997):1331-1350

[30] Melchiori, Mario R., "CreditRisk+ by Fast Fourier Transform," YieldCurve, August 2004. Available at SSRN: http://ssrn.com/abstract=1122844

[31] Miu, P., and B. Ozdemir., Basel II Implementation: A Guide to Developing and Validating a Compliant Internal Risk Rating System, McGraw-Hill Professional, (2008): 173.

[32] Moral, G., "EAD Estimates for Facilities with Explicit Limits" in Engelmann, B. and Rauhmeier, R., eds. The Basel II Risk Parameters: Estimation, Validation, and Stress Testing. New York: Springer, (2006):197-242.

[33] Qi, M., "Exposure at Default of Unsecured Credit Cards", Credit Risk Analysis Division, Office of the Comptroller of the Currency, 250 E St. SW, Washington, DC 20219; (2009)

[34] RMA - The Risk Management Association (2004) Industry Practices in Estimating EAD and LGD for Revolving Consumer Credits - Cards and Home Equity Lines of Credit. Available at http://www.rmahq.org/../RMA_EAD_LGD_Survey_Paper_FINAL.pdf

[35] Robertson, J., "The Computation of Aggregate Loss Distributions," PCAS LXXIX, (1992): 57-133.

[36] Rosen, D., and M. Sidelnikova, “Understanding Stochastic Exposures and LGD's in Portfolio Credit Risk", Algo Research Quaterly, Vol. 5, N 1, (2002):43-56.

[37] Sufi, Amir. "Bank Lines of Credit in Corporate Finance: An Empirical Analysis." The Review of Financial Studies, Vol. 22, Issue 3, (2009):1057-1088

[38] Thakor, Anjan V., Hai Hong and Stuart I. Greenbaum, "Bank Loan Commitments and Interest Rate Volatility," Journal of Banking and Finance, Vol. 5, (1981):497-510.

[39] Thakor, Anjan V., and G.F. Udell. "An Economic Rationale for the Pricing Structure of Bank Loan Commitments," Journal of Banking and Finance, vol. 11 (1987), pp. 27189. 
Appendix A

Table 1: Portfolio A

\begin{tabular}{||c|c|c|c||}
\hline \multicolumn{5}{|c|}{$\boldsymbol{\alpha}=\mathbf{1 0}, \mathbf{n}=\mathbf{1 0 0 0}$} & Rounded Put Size \\
\hline Obligor & Unused Limit (\$) & Actual Put Size & 82 \\
\hline A & 81,289 & 81.29 & 14 \\
\hline B & 13,626 & 13.63 & 21 \\
\hline C & 10,941 & 10.94 & 21 \\
\hline D & 20,709 & 20.71 & 71 \\
\hline E & 20,786 & 20.79 & 64 \\
\hline F & 70,371 & 70.37 & 66 \\
\hline G & 63,514 & 63.51 & 97 \\
\hline H & 65,435 & 65.44 & 88 \\
\hline J & 96,330 & 96.33 & 34 \\
\hline I & 87,555 & 87.56 & 41 \\
\hline J & 33,906 & 33.91 & 24 \\
\hline K & 40,567 & 40.57 & 11 \\
\hline L & 23,650 & 23.65 & 21 \\
\hline M & 10,779 & 10.78 & 8 \\
\hline N & 20,838 & 20.84 & 17 \\
\hline O & 7,602 & 7.60 & 49 \\
\hline M & 16,695 & 16.70 & 27 \\
\hline Q & 48,049 & 48.05 & 21.40 \\
\hline R & 81,403 & 26.14 & 2 \\
\hline S & 26,139 & & \\
\hline
\end{tabular}

Table 2: Portfolio B

\begin{tabular}{|c|c|c|c|}
\hline \multicolumn{4}{|c|}{$\alpha=40 \%, n=1000$} \\
\hline Obligor & Unused Limit (\$) & Actual Put Size & Rounded Put Size \\
\hline$A$ & 7,129 & 7.12 & 8 \\
\hline $\bar{B}$ & 29,253 & 29.25 & 30 \\
\hline $\mathrm{C}$ & 27,353 & 27.35 & 28 \\
\hline $\bar{D}$ & 41,340 & 41.34 & 42 \\
\hline$E$ & 2,266 & 2.26 & 3 \\
\hline$F$ & 51,946 & 51.94 & 52 \\
\hline $\bar{G}$ & 23,439 & 23.43 & 24 \\
\hline $\bar{H}$ & 70,214 & 70.21 & 71 \\
\hline $\mathrm{J}$ & 6,191 & 6.19 & 7 \\
\hline $\bar{T}$ & 55,709 & 55.7 & 56 \\
\hline $\mathrm{J}$ & 45,242 & 45.24 & 46 \\
\hline $\mathrm{K}$ & 5,861 & 5.86 & 6 \\
\hline $\mathrm{L}$ & 80,444 & 80.44 & 81 \\
\hline $\bar{M}$ & 44,273 & 44.27 & 45 \\
\hline $\bar{N}$ & 19,605 & 19.6 & 20 \\
\hline $\mathrm{O}$ & 34,828 & 34.82 & 35 \\
\hline $\bar{M}$ & 68,265 & 68.27 & 69 \\
\hline $\bar{Q}$ & 18,571 & 18.57 & 19 \\
\hline $\mathrm{R}$ & 36,324 & 36.32 & 37 \\
\hline $\mathrm{S}$ & 23,826 & 23.82 & 24 \\
\hline
\end{tabular}


Appendix B

Table 3: Descriptive Statistics of Sample Portfolio ${ }^{21}$ Limits

\begin{tabular}{||c|c|c|c||}
\hline Portfolio & A & B & $\begin{array}{c}\text { Convoluted } \\
\text { Portfolio (C) }\end{array}$ \\
\hline$\alpha$ & $10.00 \%$ & $40.00 \%$ & 360,850 \\
\hline Mean (\$) & 84,019 & 276,831 & 4,342 \\
\hline $\begin{array}{c}\text { Standard } \\
\text { Deviation (\$) }\end{array}$ & 2,287 & 3,691 & 0.0144 \\
\hline Skewness & 0.0324 & 0.0156 & 3.0005 \\
\hline Kurtosis & 3.0011 & 3.0002 & \multicolumn{2}{|l}{} \\
\hline
\end{tabular}

Figure 1: Chart for Probability Distribution of sample portfolio $A$ and $B$

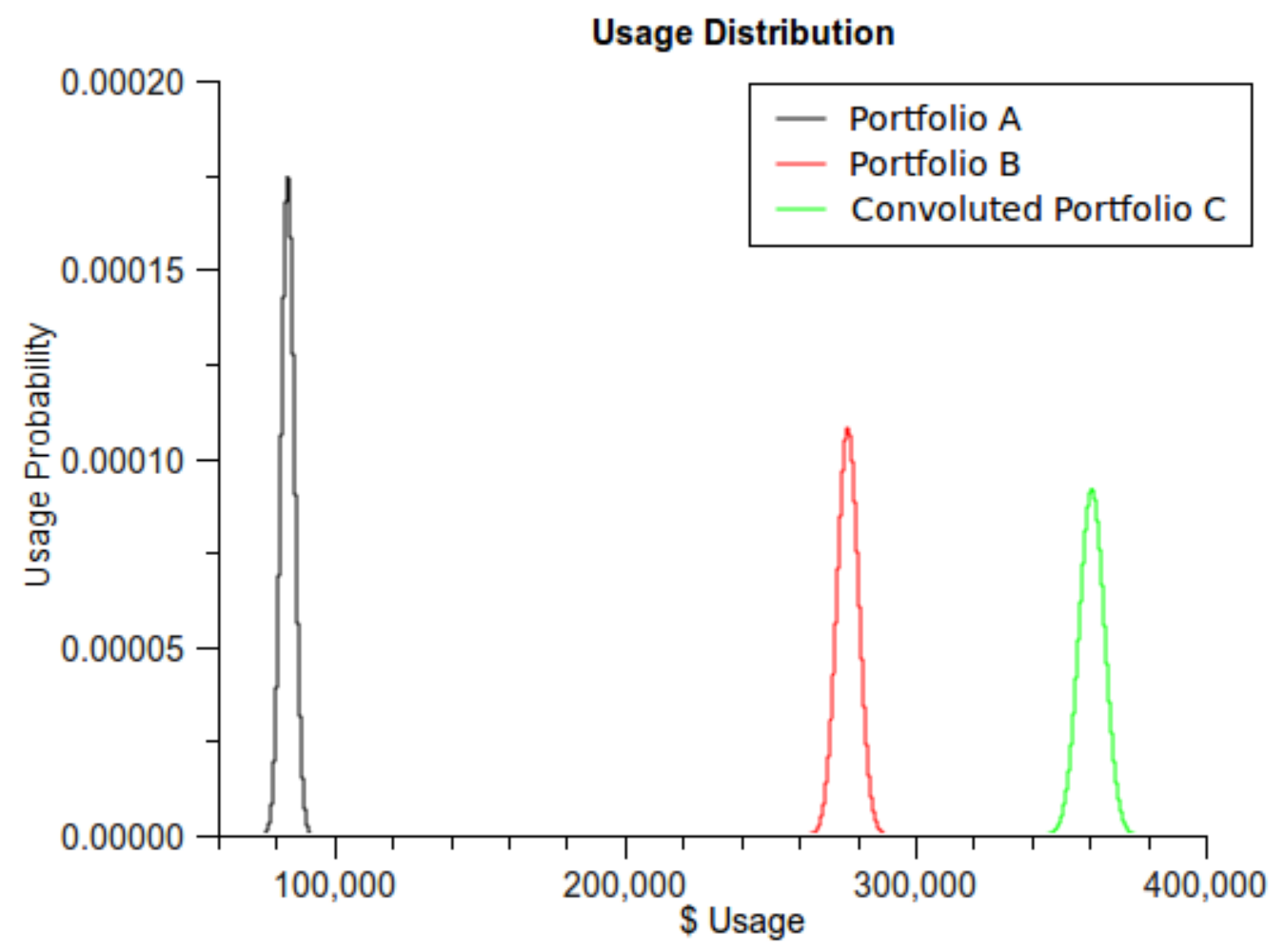

21 Here $\mathrm{n}$ is set at 1000 
Appendix C

Table 4: Variation of Usage Distribution (\$) parameters with $n^{22}$

\begin{tabular}{|c|c|c|c|c|c|c|c|c|c||}
\hline Percentile & $\mathbf{n = 7 0 0}$ & $\mathbf{n = 8 0 0}$ & $\mathbf{n = 9 0 0}$ & $\mathbf{n = 1 0 0 0}$ & $\mathbf{n}=\mathbf{1 1 0 0}$ & $\mathbf{n = 1 2 0 0}$ & $\mathbf{n = 1 3 0 0}$ & $\mathbf{n = 1 4 0 0}$ & $\mathbf{n = 1 5 0 0}$ \\
\hline $\mathbf{5 0 . 0 0 \%}$ & 14,718 & 14,720 & 14,722 & 14,723 & 14,724 & 14,726 & 14,726 & 14,726 & 14,727 \\
\hline $\mathbf{9 9 . 0 0 \%}$ & 17,272 & 17,100 & 16,970 & 16,849 & 16,741 & 16,662 & 16,583 & 16,520 & 16,460 \\
\hline $\mathbf{9 9 . 5 0 \%}$ & 17,557 & 17,364 & 17,219 & 17,084 & 16,965 & 16,874 & 16,788 & 16,718 & 16,651 \\
\hline $\mathbf{9 9 . 7 5 \%}$ & 17,823 & 17,612 & 17,452 & 17,304 & 17,173 & 17,074 & 16,978 & 16,903 & 16,829 \\
\hline $\mathbf{9 9 . 9 0 \%}$ & 18,151 & 17,916 & 17,739 & 17,574 & 17,429 & 17,320 & 17,214 & 17,130 & 17,048 \\
\hline Standard Deviation & 1,058 & 988 & 936 & 886 & 842 & 809 & 777 & 751 & 726 \\
\hline
\end{tabular}

Table 5: Variation of Usage Distribution (\$) parameters with $\alpha^{23}$

\begin{tabular}{|c|c|c|c|c|c|c|c|}
\hline Percentile & $\boldsymbol{\alpha}=\mathbf{0 . 1 0}$ & $\boldsymbol{\alpha}=\mathbf{0 . 2 0}$ & $\boldsymbol{\alpha}=\mathbf{0 . 4 0}$ & $\boldsymbol{\alpha}=\mathbf{0 . 5 0}$ & $\boldsymbol{\alpha}=\mathbf{0 . 6 0}$ & $\boldsymbol{\alpha}=\mathbf{0 . 7 0}$ & $\boldsymbol{\alpha}=\mathbf{0 . 8 0}$ \\
\hline $\mathbf{5 0 . 0 0 \%}$ & 14,724 & 29,459 & 58,929 & 73,664 & 88,400 & 103,135 & 117,870 \\
\hline $\mathbf{9 5 . 0 0 \%}$ & 16,214 & 31,552 & 61,876 & 76,955 & 92,001 & 107,023 & 122,024 \\
\hline $\mathbf{9 9 . 0 0 \%}$ & 16,850 & 32,439 & 63,116 & 78,338 & 93,513 & 108,652 & 123,764 \\
\hline $\mathbf{9 9 . 9 0 \%}$ & 17,575 & 33,445 & 64,519 & 79,901 & 95,220 & 110,492 & 125,728 \\
\hline $\mathbf{9 9 . 9 7 \%}$ & 17,904 & 33,899 & 65,151 & 80,603 & 95,987 & 111,319 & 126,610 \\
\hline $\begin{array}{c}\text { Standard } \\
\text { Deviation }\end{array}$ & 886 & 1,253 & 1,722 & 1,981 & 2,170 & 2,344 & 2,506 \\
\hline
\end{tabular}

22 Here $\alpha$ is kept constant at $10 \%$

23 Here $\mathrm{n}$ is kept constant at 1000. Lower numbers for $\mathrm{n}$ and $\alpha$ is chosen to reduce computational time taken. 